\title{
Comparison between the predicted performance curve and the Markov Chain models for structural performance of infrastructure components
}

\author{
Nabil Semaan ${ }^{1, *}$, and Youssef $\mathrm{Dib}^{2}$ \\ ${ }^{1}$ University Of Balamand, Civil and Environmental Engineering Department, Kelhat, Koura, Lebanon \\ ${ }^{2}$ University Of Balamand, Math Department, Kelhat, Koura, Lebanon
}

\begin{abstract}
This paper compares the PPC model to a Markov Chain (MC) stochastic deterioration model. First, inspection data from the Société de Transport de Montréal (STM) is gathered and analyzed. Then Transition Probability Matrices (TPM) are developed, and, using Matlab, MC deterioration curves are developed. Comparison between MC and the PPC deterioration curves is performed for subway station walls and slabs. The comparison has shown that the useful service life can be as low as 2 years for components having many inspection history records, and very high as 30 years for components having very few inspection history records. The PPC model has always a higher useful service life estimate. Also, the $\mathrm{MC}$ has a ten times higher deterioration rate ( 0.2 per year) compared to the PPC model (0.02 per year). It can be concluded that the MC deterioration model requires a high amount of inspection data, and it is mathematically difficult to generate since most practicing managers and engineers have no background in Markov Chain modeling.
\end{abstract}

\section{Introduction}

Public transit contributes substantially to the quality of life enjoyed by citizens. Although continuously growing, symptoms of aging transit infrastructure and thus overdue maintenance are becoming a burden to municipalities and governments. The American Society of Civil Engineers (ASCE) Report Card assigned a grade D- (i.e., very poor) for the public transit system in the United States (US) in 2017. The US aging infrastructure has a 90 billion USD rehabilitation backlog in 2017 , expected to grow to 122 billion USD in 2032 [1]. Hence, an urgent need of structural infrastructure management planning is required. Both assessing the structural performance of infrastructure components, and predicting the future performance of structures form the core of any infrastructure asset management.

A "Structural Performance Index" (SPI) model, developed in 2014 by Semaan and Zayed [2], was developed. The SPI model assesses both the physical condition (based on condition defects) and the functional performance (based on structural cracks) of a structural component. A "Predicted Performance Curve" (PPC), developed in 2016 by Semaan and Zayed [3], has also been developed. The PPC model evaluates the structural performance curve of a concrete component based on the SPI. The PPC utilizes a reliability-based cumulative Weibull function in order to construct the structural performance curve. The PPC can be easily developed using scarce inspection.

On the other hand, most existing infrastructure deterioration models use the Markov Chain concept.
Engineers, managers and researchers are faced with difficulties when modeling subway structures components deterioration using Markov Chain (MC. These difficulties are listed as follows: (i) difficulty of data collection, (ii) difficulty in translation of physical conditions to mathematical problems, and (iii) the Markov Chain is a memory less model, i.e. the Markov Chain model cannot show the states before the studied period and hence the current state is independent of its history. Thus PPC challenges the mostly used MC model.

The objective of this research project is to study the structural performance curve of a subway component using a Markov Chain model and compare it to an existing Predicted Performance Curve (PPC) developed by Semaan [4].

\section{Background}

Deterioration models are very important for asset management since they can predict the future performance of an asset based on both previous and current performance. Performance, by definition, is the inverse of deterioration. The performance measured as a function of time is evaluated in order to predict the service life of the component.

Service life is the predicted life of a structure before demolishing [5], [6]. The useful service life of a project is the time where all the structures' components physical, functional and safety performance are at a minimum acceptable threshold according to international standards. 


\subsection{Deterioration modelling}

Previous researchers identified three main categories of deterioration models: deterministic models, stochastic models and artificial intelligence models. Each category uses different techniques as shown in Table 1.

Table 1. Existing deterioration models and techniques.

\begin{tabular}{|c|c|}
\hline Deterioration models & Deterioration techniques \\
\hline \multirow{2}{*}{ Deterministic } & Straight-line extrapolation \\
\cline { 2 - 2 } & Regression \\
\cline { 2 - 2 } Stochastic & Curve fitting \\
\cline { 2 - 2 } & Markov Chain \\
\cline { 2 - 2 } & Reliability \\
\hline \multirow{2}{*}{ Artificial intelligence } & Artificial neural networks \\
\cline { 2 - 2 } & Case-based reasoning \\
\hline
\end{tabular}

\subsubsection{Markov chain models}

The discrete time Markov Chain (MC) technique studies the long-term behavior of two sets (space-time) that are event-independent as in the case of deterioration. The Markov Chain model is the most common stochastic model used to model infrastructures' deterioration or performance. Some widely known research that has used $\mathrm{MC}$ for different infrastructure application is given in Table 2.

Table 2. Existing research using Markov Chain models

\begin{tabular}{|c|c|}
\hline Research & Research topic \\
\hline Butt et al., 1987 [7] & Sewer deterioration \\
\hline Wirahadikusumah, 1999 [8] & Sewer deterioration \\
\hline Yang et al., 2005 [9] & Pavement deterioration \\
\hline Baik et al., 2006 [10] & Pavement deterioration \\
\hline Hong and Protzi, 2006 [11] & Pavement deterioration \\
\hline Morcous, 2006 [12] & Bridge deterioration \\
\hline Ortiz-Garcia et al., 2006 [13] & Pavement deterioration \\
\hline
\end{tabular}

The Markov Chain model translates the deterioration of an infrastructure component to a stochastic probabilistic matrix that involves time. This model collects the deterioration data from the inspection of the components over time.

In the process of understanding the MC model, $\mathrm{S}$ is defined as the set of states, $S=\left\{S_{1}, S_{2}, \ldots\right\}$. Generally, researchers consider five (5) states, $S=\left\{S_{1}, S_{2}, S_{3}, S_{4}, S_{5}\right\}$.

The MC starts by transiting from one state $S_{i}$ to another state $\mathrm{S}_{j}$ in a discrete manner. The Markov Chain defines ' $p_{j, i}$ ' as the probability of transition from state $\mathrm{S}_{i}$ to state $S_{j}$. While, for a component that remains in the same state after a certain time interval ' $t$ ', this probability is ' $p_{i, i}$ '. The probabilities for all possible transitions are gathered in one matrix called the stochastic Transition Probability Matrix (TPM).

Although the Markov Chain model is commonly used to study the performance and predict the behavior of structures with time to determine their service life, some drawbacks shall be considered. Table 3 presents the remarks on the Markov Chain principle by some researchers.

Table 3. Researchers' remarks on Markov Chain models

\begin{tabular}{|l|l|}
\hline Research & Remarks \\
\hline $\begin{array}{l}\text { Sianipar and Adams, 1997 [14] } \\
\text { Van Noortwijk and Frangopol, }\end{array}$ & $\begin{array}{l}\text { It is difficult to } \\
\text { consider the } \\
\text { interactions between } \\
\text { components }\end{array}$ \\
\hline $\begin{array}{l}\text { Madanat } \text { et al., 1997 [16] } \\
\text { Destephano and Grivas, 1998 [17] }\end{array}$ & $\begin{array}{l}\text { It assumes that each } \\
\text { state is independent }\end{array}$ \\
\hline Madanat and Ibrahim, 1995 [18] & $\begin{array}{l}\text { It does not predict } \\
\text { the condition } \\
\text { improvement after } \\
\text { repair }\end{array}$ \\
\hline \multirow{2}{*}{ Tokdemir et al., 2000 [19] } & $\begin{array}{l}\text { The transition } \\
\text { probabilities are } \\
\text { estimated in terms of } \\
\text { subjective } \\
\text { engineering } \\
\text { judgment and require } \\
\text { updating when new } \\
\text { data is obtained }\end{array}$ \\
\hline
\end{tabular}

Hence, Markov Chain models, although highly used, are data hungry, requiring a very large amount of data in order to develop the TPM. In the case of subway network infrastructure components, collecting inspection data is to be done only when the station is closed after midnight. Thus, collecting a very large sample for subway stations requires more inspection time on one hand, and frequent inspections on the other, which incurs a high cost.

Also, most practicing managers and engineers have no background in Markov chain mathematical modeling, making it difficult to implement it, especially, again to subway networks.

Finally, the Markov Chain method cannot show the states before the studied period, so that the current state is independent of its history. Thus it is a memory-less technique.

\subsubsection{The Predicted Performance Curve (PPC) model}

Semaan and Zayed (2016) [3] developed the Predicted Performance Curve (PPC). The PPC develops a performance (or deterioration) curve of the structural components of concrete infrastructure. The PPC uses the Weibull distribution cumulative function in order to develop a structural performance curve. In order to construct the PPC, three steps are needed: i) develop an Ideal Performance Curve (IPC) using a Weibull 
distribution cumulative function; ii) introduce to the Ideal Performance Curve (IPC) at least one set of inspection data in order to develop an Updated Performance Curve (UPC); iii) after the last inspection data is introduced the PPC is obtained.

The main objective of a Predicted Performance Curve (PPC) model is that it predicts the structural deterioration of concrete components and their useful estimated service life.

The Predicted Performance Curve (PPC) model is based on a structural component assessment index model which was developed by Semaan and Zayed (2014) [2]. Their model combines a physical condition (based on condition defects) performance index, and a functional index. Then, this model combines these two indices into one - the "integrated performance index" $\mathrm{P}_{\mathrm{I}}$. Semaan and Zayed (2014) [2] stressed that although $P_{I}$ is applied to subway components, it can generically be used for any infrastructure concrete component. The model assesses the components' performance based on the integration of the physical performance with the functional one. Hence, an integrated performance index could be used for the assessment of any infrastructure system.

The Ideal Performance Curve is defined in Equation 1.

$$
P_{I}(t)^{I P C}=1 \cdot e^{\left[\frac{\ln (0.2) t^{3}}{100^{3}}\right]}
$$

\section{Where: $\quad P_{I}$ is Performance index IPC is Ideal Performance Curve $t$ is time}

When $t$ equals zero, the equation gives a $\mathrm{P}_{\mathrm{I}}$ value of 1.0 which is the maximum, and it is usually achieved when the element is first constructed. When ' $t$ ' equals 100 years, $\mathrm{P}_{\mathrm{I}}$ is ideally estimated at 0.2 which means that the components inspected are at their minimum performance. The model also assumes that at the time where $P_{I}$ has a value of 0.4 , the useful service life or the performance threshold has been reached.

The curve representing the IPC is illustrated in Figure 1.

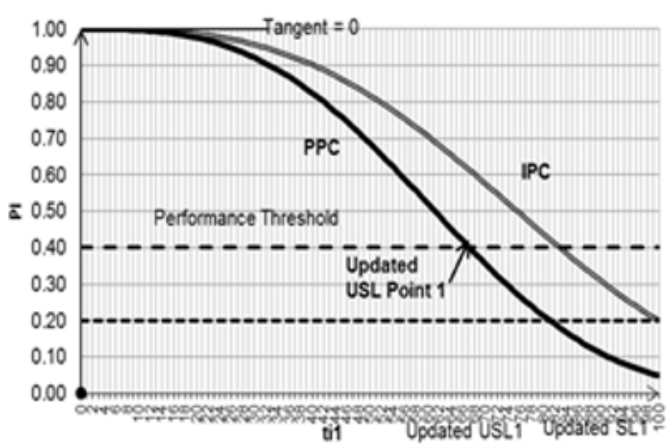

Fig. 1. The Ideal Performance Curve (IPC).

The Predicted Performance Curve uses Equation 2, as follows:

$$
P_{I}(t)^{P P C}=1 \cdot e^{\ln \left(P_{I i}\right)\left(t / t_{i}\right)^{3}}
$$

This curve is an update of the ideal performance curve after each inspection has been made. When each value of a $P_{I}$ is calculated, it is plotted in the graph and then a new curve is drawn passing through that point. Figure 2 shows an example of such a curve.

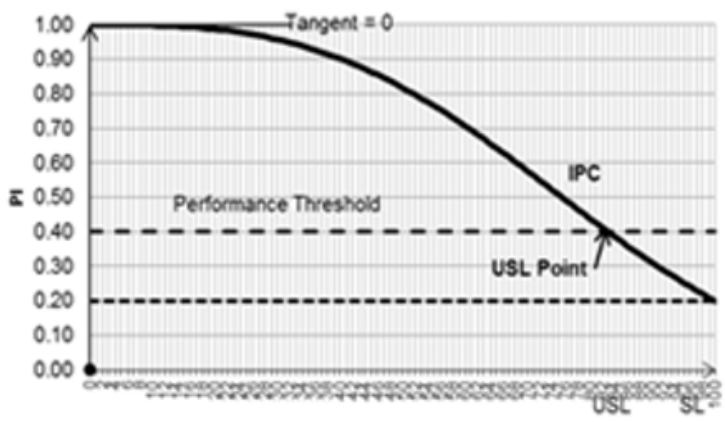

Fig. 2. The Predicted Performance Curve (PPC).

\section{Markov Chain deterioration curves of subway structure components}

A deterioration curve for subway structural components has also been developed using a stochastic Markov Chain model entitled the 'Subway Structures Markov Chain Deterioration Model' (SSMCD). Figure 3 illustrates the SSMCD Model methodology.

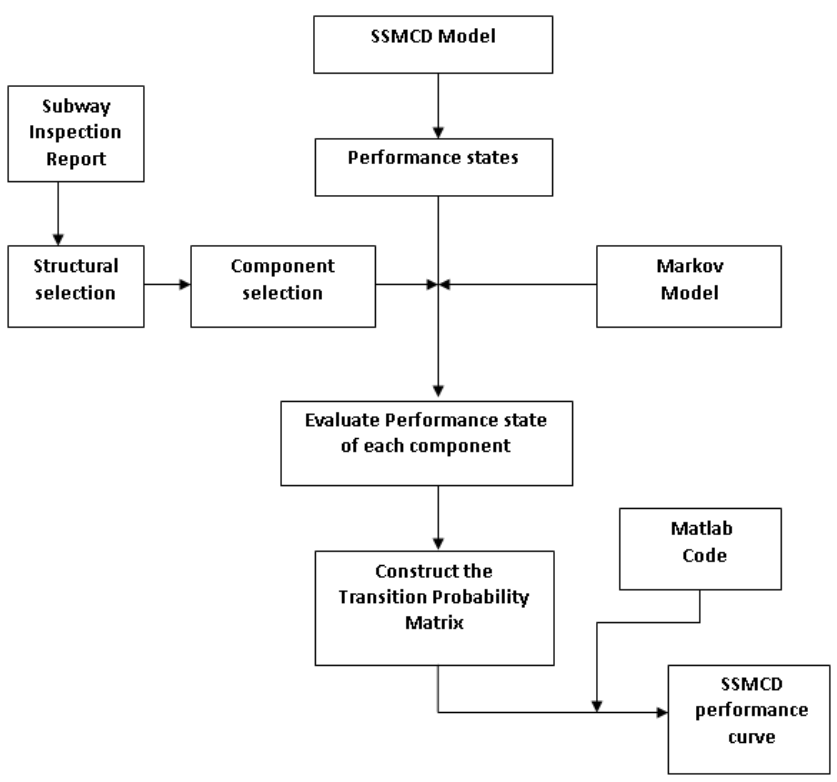

Fig. 3. The Subway Structure Markov Chain Deterioration (SSMCD) model flowchart

A Markov Chain considers discrete deterioration states. A deterioration state can be identified only in the following states and cannot have a condition in between states. Table 3 illustrates the SSMCD deterioration states in relation to the Integrated Performance Index $\left(\mathrm{P}_{\mathrm{I}}\right)$ and its respective performance description. 
Table 3. Definitions of the state's deterioration

\begin{tabular}{c|c|l}
$\begin{array}{c}\text { Deterioration } \\
\text { states }\end{array}$ & $\begin{array}{c}\text { Integrated } \\
\text { Performance } \\
\text { Index (PI) }\end{array}$ & $\begin{array}{l}\text { Description of } \\
\text { deterioration states }\end{array}$ \\
\hline State 1 $\left(\mathrm{S}_{1}\right)$ & 1.0 & $\begin{array}{l}\text { Very good condition } \\
\text { Very low deterioration }\end{array}$ \\
\hline State 2 $\left(\mathrm{S}_{2}\right)$ & 0.8 & $\begin{array}{l}\text { Good condition } \\
\text { Low deterioration }\end{array}$ \\
\hline State 3 $\left(\mathrm{S}_{3}\right)$ & 0.6 & $\begin{array}{l}\text { Average condition } \\
\text { Average deterioration }\end{array}$ \\
\hline State 4 $\left(\mathrm{S}_{4}\right)$ & 0.4 & $\begin{array}{l}\text { Low condition } \\
\text { High deterioration }\end{array}$ \\
\hline State 5 $\left(\mathrm{S}_{5}\right)$ & 0.2 & $\begin{array}{l}\text { Very low condition } \\
\text { Very high } \\
\text { deterioration }\end{array}$
\end{tabular}

Table 3 shows that a $\mathrm{P}_{\mathrm{I}}$ of 0.4 means a high deterioration, meaning public security is at risk. Hence structural components having a $\mathrm{P}_{\mathrm{I}}$ less than 0.4 are not meeting their functional and physical performance; i.e. are in urgent need of rehabilitation. Moreover, if maintenance and rehabilitation were not done at these structural components, deterioration could be as low as 0.2 . In this case the component is to be replaced completely and/or reconstructed. Managers should not let this case happen at all.

The first step in the Transition Probability Matrix (TPM) development is to divide the data into discrete time intervals: from year of construction to the first inspection period, and then from first inspection to second inspection, and so on. Next, in each time interval, analyze the transition of states from state $\left(S_{i}\right)$ to state $\left(S_{j}\right)$, where state $\left(S_{i}\right)$ is an initial state at the time of previous inspection, or at the year of construction $\left(S_{1}\right)$. While, state $\left(S_{j}\right)$ is the condition state an element reached after a certain time interval ' $t$ '. The possible state transition is illustrated in Figure 4. The arrow represents a one direction transition from a state to another, since no structural improvement is considered.

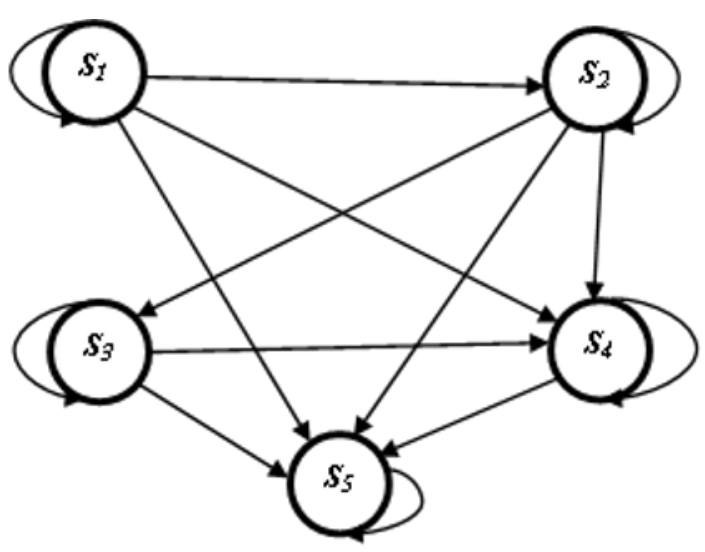

Fig. 4. Possible Deterioration State Transition

A probability of occurrence is evaluated for each transition from state $S i$ to state $S j$, as per Equation 3.

$$
p_{j \cdot i}=\frac{N E_{j \cdot i}}{\sum N E}
$$

Where: $p_{j, i}$ is the probability of transition from state $S_{i}$ to state $S_{j}$,

$N E_{j, i}$ is the number of structural components moving from state $S_{i}$ to state $S_{j}$ in the time interval

$N E$ is the total number of structural components under consideration.,

Referring to the possible state transitions in Figure 4, and Equation 3, a typical TPM is evaluated as shown in Table 4.

Table 4. The SSMCD Typical Transition Probability Matrix

$$
\begin{array}{l|ccccc}
\multicolumn{1}{c}{} & S_{1} & S_{2} & S_{3} & S_{4} & S_{5} \\
\cline { 2 - 3 } S_{1} & p_{1,1} & 0 & 0 & 0 & 0 \\
S_{2} & p_{2,1} & p_{2,2} & 0 & 0 & 0 \\
S_{3} & p_{3,1} & p_{3,2} & p_{3,3} & 0 & 0 \\
S_{4} & p_{4,1} & p_{4,2} & p_{4,3} & p_{4,4} & 0 \\
S_{5} & p_{5,1} & p_{5,2} & p_{5,3} & p_{5,4} & 1 \\
\cline { 5 - 7 }
\end{array}
$$

Finally, using the TPM, the SSMCD uses Matlab in order to develop the element deterioration curves.

\section{The SSMCD application to the Société Transport de Montréal (STM)}

The SSMCD model has been applied to the Société de Transport de Montréal (STM) stations. Three stations were selected, and structural slabs and walls components were chosen. Deterioration curves using Markov Chain were developed for the both the structural slabs and wall components. Table 5 shows information of each station, mainly the name, construction year, inspection periods, and number of structural slabs and wall components.

Table 5. STM Stations Information

\begin{tabular}{|l|c|c|c|c|}
\hline Station & $\begin{array}{c}\text { Construction } \\
\text { Year }\end{array}$ & $\begin{array}{c}\text { Inspection } \\
\text { Years }\end{array}$ & $\begin{array}{c}\text { Number } \\
\text { of Slabs }\end{array}$ & $\begin{array}{c}\text { Number } \\
\text { of Walls }\end{array}$ \\
\hline Beaudry & 1966 & $\begin{array}{c}1992 \\
1997 \\
2005\end{array}$ & 44 & 34 \\
\hline Sherbrooke & 1966 & $\begin{array}{c}1997 \\
2005\end{array}$ & 16 & 14 \\
\hline $\begin{array}{l}\text { Champs- } \\
\text { de-Mars }\end{array}$ & 1966 & $\begin{array}{c}1997 \\
2005\end{array}$ & 8 & 14 \\
\hline
\end{tabular}

Applying the SSMCD model, the TPM for the components under consideration are developed. Tables 6 to 11 show the TPM of each station components. 
Table 6. TPM of Beaudry Station Slab Components

\begin{tabular}{c|cccccc}
\multicolumn{1}{c}{} & \multicolumn{1}{c}{$S_{1}$} & $S_{2}$ & $S_{3}$ & $S_{4}$ & $S_{5}$ \\
\cline { 2 - 4 } \cline { 5 - 6 }$S_{1}$ & $20 / 44$ & 0 & 0 & 0 & 0 \\
$S_{2}$ & $22 / 44$ & $20 / 44$ & 0 & 0 & 0 \\
$S_{3}$ & $1 / 44$ & $22 / 44$ & $20 / 44$ & 0 & 0 \\
$S_{4}$ & $1 / 44$ & $1 / 44$ & $22 / 44$ & $22 / 44$ & 0 \\
$S_{5}$ & 0 & $1 / 44$ & $2 / 44$ & $22 / 44$ & 1 \\
\cline { 6 - 6 }
\end{tabular}

Table 7. TPM of Beaudry Station Wall Components

\begin{tabular}{c|cccccc}
\multicolumn{1}{c}{} & \multicolumn{1}{c}{$S_{1}$} & $S_{2}$ & $S_{3}$ & $S_{4}$ & $S_{5}$ \\
\cline { 2 - 3 } \cline { 5 - 6 }$S_{1}$ & $16 / 34$ & 0 & 0 & 0 & 0 \\
$S_{2}$ & $18 / 34$ & $16 / 34$ & 0 & 0 & 0 \\
$S_{3}$ & 0 & $18 / 34$ & $16 / 34$ & 0 & 0 \\
$S_{4}$ & 0 & 0 & $18 / 34$ & $16 / 34$ & 0 \\
$S_{5}$ & 0 & 0 & 0 & $18 / 34$ & 1 \\
\cline { 5 - 6 } & & & & & &
\end{tabular}

Table 8. TPM of Sherbrooke Station Slab Components

\begin{tabular}{l|cccccc}
\multicolumn{1}{c}{} & $S_{1}$ & $S_{2}$ & $S_{3}$ & $S_{4}$ & $S_{5}$ \\
\cline { 2 - 3 }$S_{1}$ & $8 / 16$ & 0 & 0 & 0 & 0 \\
$S_{2}$ & $1 / 16$ & & $8 / 16$ & 0 & 0 & 0 \\
$S_{3}$ & $7 / 16$ & $1 / 16$ & $8 / 16$ & 0 & 0 \\
$S_{4}$ & 0 & $7 / 16$ & $1 / 16$ & $8 / 16$ & 0 \\
$S_{5}$ & 0 & 0 & $7 / 16$ & $8 / 16$ & 1 \\
\hline
\end{tabular}

Table 9. TPM of Sherbrooke Station Wall Components

\begin{tabular}{l|cccccc}
\multicolumn{1}{c}{} & $S_{1}$ & $S_{2}$ & $S_{3}$ & $S_{4}$ & $S_{5}$ \\
\cline { 2 - 3 } \cline { 5 - 7 }$S_{1}$ & $12 / 14$ & 0 & 0 & 0 & 0 \\
$S_{2}$ & 0 & $14 / 14$ & 0 & 0 & 0 \\
$S_{3}$ & $2 / 14$ & 0 & $14 / 14$ & 0 & 0 \\
$S_{4}$ & 0 & $2 / 14$ & 0 & $12 / 14$ & 0 \\
$S_{5}$ & 0 & 0 & $2 / 14$ & $2 / 14$ & 1 \\
\cline { 6 - 7 }
\end{tabular}

Table 10. TPM of Champs-de-Mars Station Slab Components

\begin{tabular}{l|cccccc}
\multicolumn{1}{c}{} & \multicolumn{1}{c}{$S_{1}$} & & $S_{2}$ & $S_{3}$ & $S_{4}$ & $S_{5}$ \\
\cline { 2 - 3 } \cline { 5 - 7 }$S_{1}$ & $3 / 8$ & & 0 & 0 & 0 & 0 \\
$S_{2}$ & $3 / 8$ & & $3 / 8$ & 0 & 0 & 0 \\
$S_{3}$ & $2 / 8$ & & $3 / 8$ & $3 / 8$ & 0 & 0 \\
$S_{4}$ & 0 & & $2 / 8$ & $3 / 8$ & $3 / 8$ & 0 \\
$S_{5}$ & 0 & 0 & $2 / 8$ & $5 / 8$ & 1 \\
\cline { 5 - 7 }
\end{tabular}

Table 11. TPM of Champs-de-Mars Station Wall Components

\begin{tabular}{l|cccccc}
\multicolumn{1}{l}{} & $S_{1}$ & $S_{2}$ & $S_{3}$ & $S_{4}$ & $S_{5}$ \\
\cline { 2 - 3 } \cline { 5 - 7 }$S_{1}$ & $8 / 14$ & 0 & 0 & 0 & 0 \\
$S_{2}$ & $3 / 14$ & & $8 / 14$ & 0 & 0 & 0 \\
$S_{3}$ & $3 / 14$ & $3 / 14$ & $8 / 14$ & 0 & 0 \\
$S_{4}$ & 0 & $3 / 14$ & $3 / 14$ & $8 / 14$ & 0 \\
$S_{5}$ & 0 & 0 & $3 / 14$ & $6 / 14$ & 1 \\
\hline
\end{tabular}

\section{SSMCD versus PPC deterioration curves}

The deterioration curves using SSMCD developed for the structural slab and wall components for each station, are compared to the deterioration curves developed using PPC. Both deterioration curves are plotted on the same Figure for comparison purposes. It should be noted that the developed PPC deterioration curves are developed for each structural component separately. Thus, the figure shows PPC curves for external slabs (SE), internal slabs (SI), external walls (WE), and internal walls (WI) of each level (i.e. SE0, SE1, SE2, etc...).

Figures 5 to 10 show the MC and PPC deterioration curves of the subway stations structural components of the three stations.

The dotted lines illustrate the PPC curve, and the bold full line the SSMCD curve.

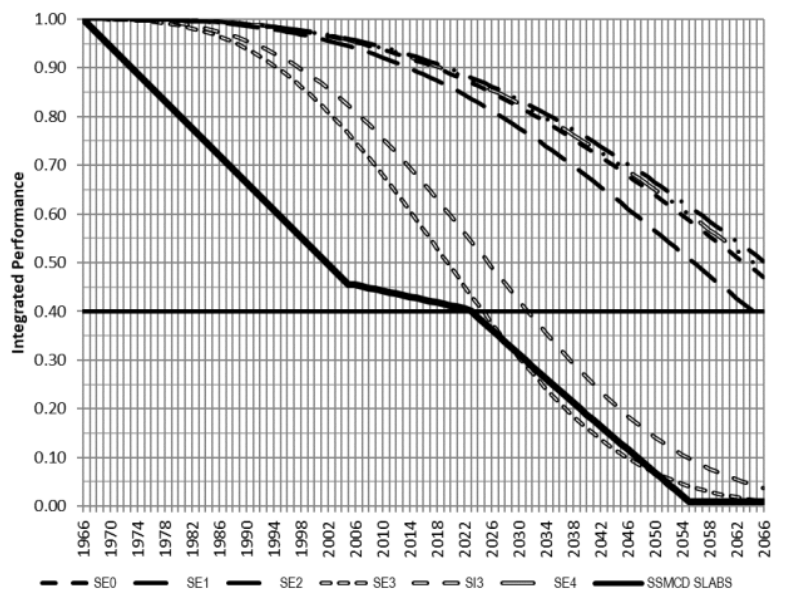

Fig. 5. Beaudry Station Slabs SSMCD vs PPC Deterioration Curves

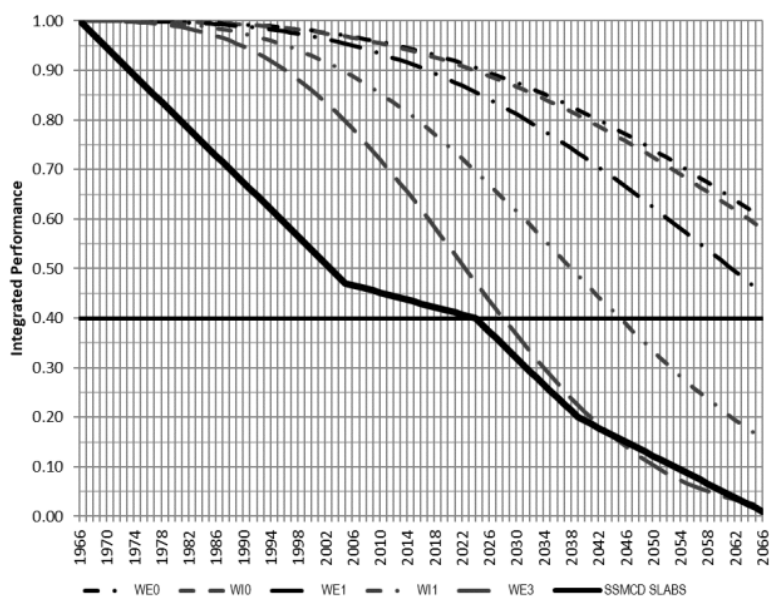

Fig. 6. Beaudry Station Walls SSMCD vs PPC Deterioration Curves 


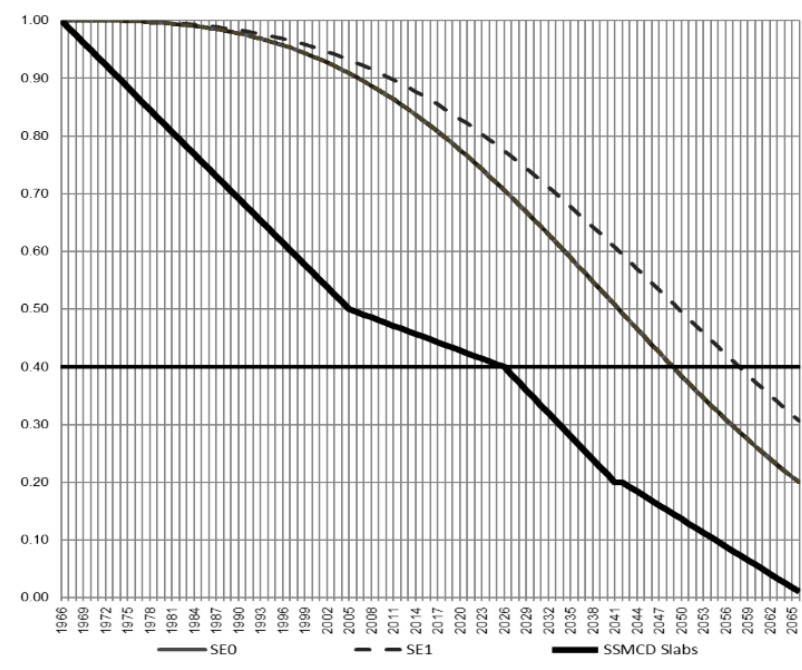

Fig. 7. Sherbrooke Station Slabs SSMCD vs PPC Deterioration Curves

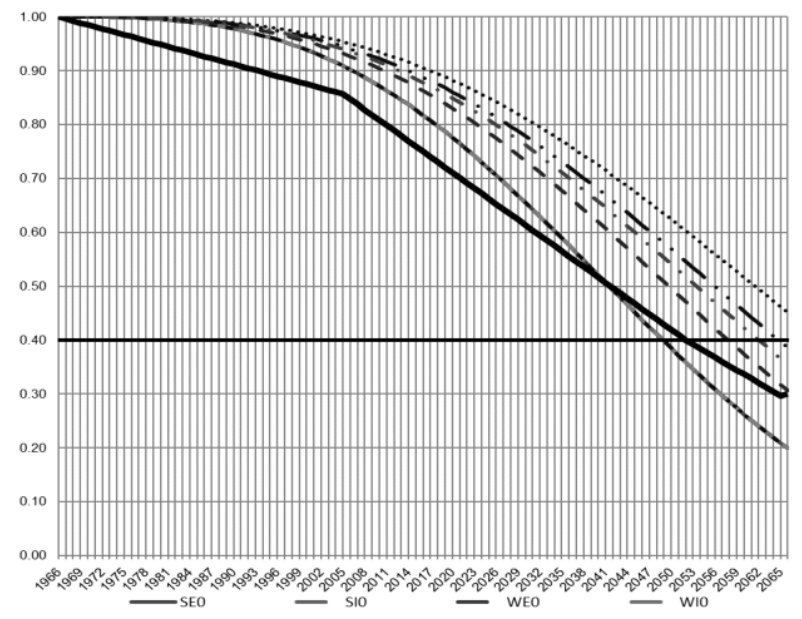

Fig. 8. Sherbrooke Station Walls SSMCD vs PPC Deterioration Curves

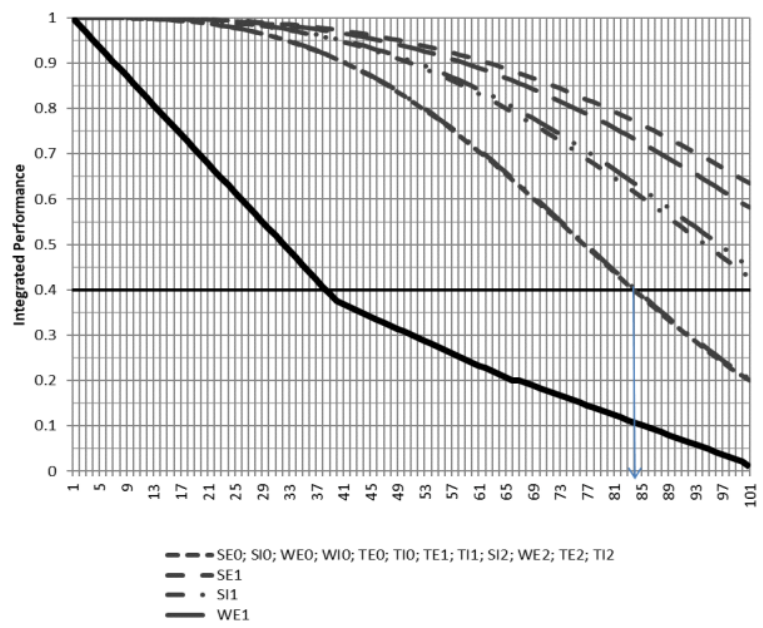

Fig. 9. Champs-de-Mars Station Slabs SSMCD vs PPC Deterioration Curves

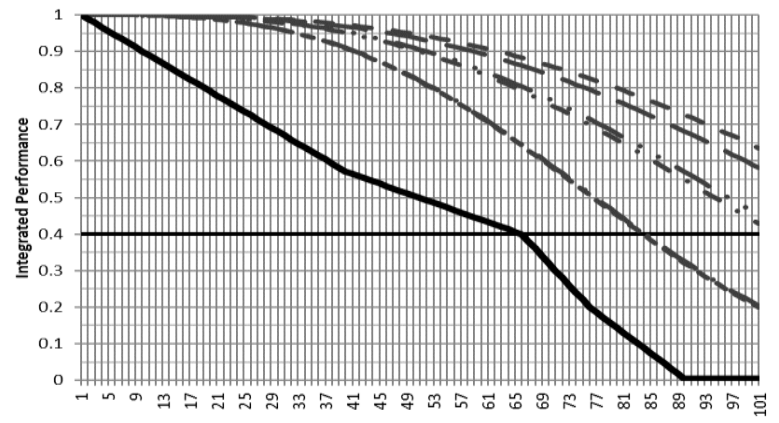

- - SEO; SIO; WEO; WIO; TEO; TIO; TE1; TI1; SI2; WE2; TE2; TI2 \begin{tabular}{l}
$-\mathrm{SE1}$ \\
$\mathbf{S} \mathrm{SI}$ \\
\hline
\end{tabular} WI1

Fig. 10. Champs-de-Mars Station Walls SSMCD vs PPC Deterioration Curves

The comparison between the SSMCD and PPC deterioration curves is analyzed for each station and type of structural component, and summarized in Tables 12 to 17. Three parameters are compared and analyzed: (i) the Service Life which is the year when the element reaches a performance index of 0.2 , i.e. highly deteriorated, (ii) the Useful Service Life which is the year when the element reaches a performance index of 0.4 , i.e. not highly deteriorated but not safe to public, and (iii) the deterioration rate which is the change of the performance index per unit of time.

Table 12. Beaudry Station Slabs SSMCD vs PPC Comparison

\begin{tabular}{|l|c|c|c|}
\hline Model & $\begin{array}{c}\text { Service } \\
\text { Life }\end{array}$ & $\begin{array}{c}\text { Useful } \\
\text { Service Life }\end{array}$ & $\begin{array}{c}\text { Deterioration } \\
\text { Rate }\end{array}$ \\
\hline SSMCD & 2039 & 2023 & 0.2 per year \\
\hline PPC & 2037 & 2025 & 0.03 per year \\
\hline
\end{tabular}

Table 13. Beaudry Station Walls SSMCD vs PPC Comparison

\begin{tabular}{|l|c|c|c|}
\hline Model & $\begin{array}{c}\text { Service } \\
\text { Life }\end{array}$ & $\begin{array}{c}\text { Useful } \\
\text { Service Life }\end{array}$ & $\begin{array}{c}\text { Deterioration } \\
\text { Rate }\end{array}$ \\
\hline SSMCD & 2039 & 2024 & 0.2 per year \\
\hline PPC & 2040 & 2028 & 0.03 per year \\
\hline
\end{tabular}

Table 14. Sherbrooke Station Slabs SSMCD vs PPC Comparison

\begin{tabular}{|l|c|c|c|}
\hline Model & $\begin{array}{c}\text { Service } \\
\text { Life }\end{array}$ & $\begin{array}{c}\text { Useful } \\
\text { Service Life }\end{array}$ & $\begin{array}{c}\text { Deterioration } \\
\text { Rate }\end{array}$ \\
\hline SSMCD & 2042 & 2026 & 0.2 per year \\
\hline PPC & 2066 & 2049 & 0.02 per year \\
\hline
\end{tabular}

Table 15. Sherbrooke Station Walls SSMCD vs PPC Comparison

\begin{tabular}{|l|c|c|c|}
\hline Model & $\begin{array}{c}\text { Service } \\
\text { Life }\end{array}$ & $\begin{array}{c}\text { Useful } \\
\text { Service Life }\end{array}$ & $\begin{array}{c}\text { Deterioration } \\
\text { Rate }\end{array}$ \\
\hline SSMCD & - & 2052 & 0.04 per year \\
\hline PPC & - & 2049 & 0.02 per year \\
\hline
\end{tabular}


Table 16. Champs-de-Mars Station Slabs SSMCD vs PPC Comparison

\begin{tabular}{|l|c|c|c|}
\hline Model & $\begin{array}{c}\text { Service } \\
\text { Life }\end{array}$ & $\begin{array}{c}\text { Useful } \\
\text { Service Life }\end{array}$ & $\begin{array}{c}\text { Deterioration } \\
\text { Rate }\end{array}$ \\
\hline SSMCD & 2031 & 2020 & 0.28 per year \\
\hline PPC & - & 2050 & 0.02 per year \\
\hline
\end{tabular}

Table 17. Champs-de-Mars Station Walls SSMCD vs PPC Comparison

\begin{tabular}{|l|c|c|c|}
\hline Model & $\begin{array}{c}\text { Service } \\
\text { Life }\end{array}$ & $\begin{array}{c}\text { Useful } \\
\text { Service Life }\end{array}$ & $\begin{array}{c}\text { Deterioration } \\
\text { Rate }\end{array}$ \\
\hline SSMCD & 2051 & 2031 & 0.16 per year \\
\hline PPC & 2066 & 2049 & 0.02 per year \\
\hline
\end{tabular}

Analyzing the Useful Service Life prediction, it can be noticed than a difference of 2 years (between SSMCD and PPC) exist for components having many historical inspection records. While, the USL can reach a difference of 30 years for components having very few (to no) historical inspection records. This fact proves that the SSMCD deterioration curve does not accurately predict the USL when few data are available. It can be also observed that the PPC predicts a further USL than SSMCD.

On the other hand, the deterioration rate of PPC is around ten (10) less than that of SSMCD. This observation confirms the fact that the discrete $\mathrm{MC}$ model for few inspections data is more conservative.

Also, although the SSMCD in Figures 5 to 10 connects the line to the construction time $(t=0)$, in reality, this line does not exist, due to the independency of past states to the current states.

\section{Conclusions and recommendations}

A Markov Chain deterioration model for the structural components of infrastructure has been developed, entitled the Subway Station Markov Chain Model (SSMCD). The SSMCD model has been applied to the Société de Transport de Montréal (STM) stations. Then the SSMCD is compared to the developed PPC deterioration model for subway networks.

Comparing both deterioration models, it is observed that the PPC is more accurate, requires less historical inspection records, is easier to develop, relates historical deteriorated states to current ones and predicts service life easily.

The Markov Chain model was found mathematically complicated to apply, and less accurate for small historical inspection records.

Thus, the PPC is highly recommended as a new deterioration model for infrastructure components.

\section{References}

1. ASCE, www.asce.org/reportcard/2017, (2017)

2. N. Semaan, T. Zayed, Int. Jour. Sci. Env. And Tech., 3, 6, pp. 1943-1968, (2014)

3. N. Semaan, T. Zayed, Proceedings of Concrete Solutions, 6th Int. Conf. on Conc. Rep., Taylor \& Francis, pp. 429-436, (2016)
4. N. Semaan, Structural Performance Model for Subway Networks, Concordia University Ph.D. Thesis, (2011)

5. A. Sarja, E. Vesikari, Durability Design of Concrete Structures, RILEM report 14, Technical Research Center of Finland, E\&FNSpon, (1996)

6. W. R. Hudson, R. Hass, W. Uddin, Infrastructure Management, McGraw Hill, NY, USA, (1997)

7. A. A. Butt, M. Y. Shahin, K. J. Feighan, S. H. Carpenter, Jour. Trans. Res. Boa., 1123, pp. 12-19, (1987)

8. R. Wirahadikusumah, Jour. Per. Cons. Fac., 23, 1, pp. 47-54, (2009)

9. J. Yang, M. Gunaratne, J. J. Lu, B. Dietrich, Jour. Trans. Eng., 131, 11, 99. 861-872, (2005)

10. H. Baik, H. S. Jeong, D. Abraham, Jour. Wat. Res. Plan. Man., 23, 1, pp. 15-24, (2006)

11. F. Hong, J. Prozzi, Jour. Inf. Man., 12, 2, pp. 77-86, (2006)

12. G. Mourcos, Jour. Per. Cons. Fac., 20, 2, pp. 146-155, (2006)

13. J. Ortiz-Garcia, S. B. Costello, M. S. Snaith, Jour. Trans. Eng., 132, 2, pp. 141-161, (2006)

14. P. M. M. Sianipar, T. M. Adams, Jour. Inf. Sys., 3, 3, pp. 103-110, (1997)

15. J. M. Van Noortwijk, D. M. Frangopol, Prob. Eng. Mech., 19, 4, pp. 345-359, (2004)

16. S. Madanat, M. Karlaftis, P. S. McCarthy, Jour. Inf. Sys., 1, 3, pp.4-9, (1997)

17. P. D. DeStephano, D. A. Grivas, Jour. Inf. Sys., 4, 2, pp. 56-62, (1998)

18. S. Madanat, W. H. W. Ibrahim, Jour. Transp. Eng., 121, 3, pp. 267-272, (1995)

19. O. B. Tokdemir, C. Ayvalik, J. Mahammadi, Poc. $17^{\text {th }}$ Int. Symp. on Auto and Rob. in Cons., pp. 10911098. 